\title{
Bulk-like endocytosis plays an important role in the recycling of insulin granules in pancreatic beta cells
}

\author{
Du Wen ${ }^{1,4}$, Yanhong Xue ${ }^{1,4}$, Kuo Liang $^{3}$, Tianyi Yuan ${ }^{2}$, Jingze Lu ${ }^{1}$, Wei Zhao ${ }^{1,4}$, Tao Xu ${ }^{1 凶}$, Liangyi Chen ${ }^{2}$ \\ ${ }^{1}$ National Key Laboratory of Biomacromolecules, Institute of Biophysics, Chinese Academy of Sciences, Beijing 100101, China \\ ${ }^{2}$ Lab of Cell Secretion and Metabolism, Institute of Molecular Medicine, Peking University and National Center for Nanoscience \\ and Technology, Beijing, 100871, China \\ ${ }^{3}$ Department of General Surgery, Xuanwu Hospital, Capital Medical University, Beijing 100053, China \\ ${ }^{4}$ Graduate School of the Chinese Academy of Sciences, Beijing 100864, China \\ $\triangle$ Correspondence: lychen@pku.edu.cn (L. Chen); xutao@ibp.ac.cn (T. Xu) \\ Received May 6, 2012 Accepted May 10, 2012
}

\begin{abstract}
Although bulk endocytosis has been found in a number of neuronal and endocrine cells, the molecular mechanism and physiological function of bulk endocytosis remain elusive. In pancreatic beta cells, we have observed bulk-like endocytosis evoked both by flash photolysis and trains of depolarization. Bulk-like endocytosis is a clathrin-independent process that is facilitated by enhanced extracellular $\mathrm{Ca}^{2+}$ entry and suppressed by the inhibition of dynamin function. Moreover, defects in bulklike endocytosis are accompanied by hyperinsulinemia in primary beta cells dissociated from diabetic KKAy mice, which suggests that bulk-like endocytosis plays an important role in maintaining the exo-endocytosis balance and beta cell secretory capability.
\end{abstract}

KEYWORDS bulk-like endocytosis, clathrin-independent endocytosis, dynamin, diabetic KKAy mice

\section{INTRODUCTION}

After secretory vesicles fuse with the plasma membrane, membrane retrieval must occur to maintain a constant cell size and to facilitate the reuse of vesicular membrane components. In the past three decades, at least three types of vesicle recycling processes have been found in excitable cells, such as neuronal and endocrine cells. These processes include clathrin-dependent endocytosis and two types of clathrin-independent endocytosis: kiss and run endocytosis and bulk endocytosis (Royle and Lagnado, 2003). Among these clathrin-independent types of membrane retrieval, bulk endocytosis is a relatively new concept, which was first proposed by Takei et al. in 1996 (Clayton and Cousin, 2009). Using electron microscopy to observe nerve terminals, Takei et al. observed stimulation-evoked internalization of larger areas of plasma membrane as endosomes from which multiple vesicles could subsequently bud off. Unlike clathrin-mediated endocytosis, bulk retrieval is often triggered by high-frequency membrane depolarization (Clayton et al., 2008), and its formation does not directly involve clathrin (Royle and Lagnado, 2003). Bulk endocytosis has been reported in various neuronal systems, including hippocampal neurons (Takei et al., 1996), retinal bipolar cells (Paillart et al., 2003), neuromuscular junctions (Teng et al., 1999; Richards et al., 2000), and the calyx of Held (Wu and Wu, 2007). Despite the widespread existence of bulk endocytosis cell types, the functional significance of bulk endocytosis in specific physiological processes has not been demonstrated.

In pancreatic beta cells, stimulated insulin secretion has been found to be coupled with enhanced vesicle recycling processes (Orci et al., 1973). Recently, we have shown that elevated $\left[\mathrm{Ca}^{2+}\right]_{\mathrm{i}}$ triggers both clathrin-dependent slow endocytosis and clathrinindependent fast endocytosis in pancreatic beta cells (He et al., 2008). However, whether clathrin-independent endocytosis plays a role in the recycling of insulin vesicles under physiologically relevant stimulation remains to be determined.

In the present study, we show that both flash photolysis and depolarization pulses evoke bulk-like endocytosis in primary pancreatic beta cells. The frequency but not the amplitude of the bulk-like retrieval events is increased by an 
increase in the intracellular $\mathrm{Ca}^{2+}$ concentration and inhibited by dynasore (dynamin blocker). In addition, we found significant inhibition of depolarization-induced bulk-like endocytosis in hyperinsulinemic beta cells isolated from diabetic KKAy mice compared with age-matched C57 controls, which suggested a role of bulk-like endocytosis in maintaining beta cell function during the development of diabetes.

\section{RESULTS}

\section{Flash photolysis and depolarization can elicit clathrin- independent bulk-like endocytosis}

Similar to a previous report from our group (He et al., 2008), homogenously elevating $\left[\mathrm{Ca}^{2+}\right]_{i}$ in primary beta cells via controlled UV photolysis ("uncaging") of 1-(4,5-dimethoxy-2nitrophenyl)-1,2-diaminoethane-N,N,-N', $\mathrm{N}^{\prime}$-tetraacetic acid (DMNP-EDTA) evoked excessive membrane retrieval, which contains a fast and a slow component (Fig. 1A). By magnifying the capacitance trace in the time scale, step-like decreases in capacitance were frequently observed in the rapid declining phase (Fig. 1A). These downward capacitance shifts were not accompanied by the alteration of membrane conductance $(\mathrm{Gm}$, Fig. $1 \mathrm{~A})$ and may occur concomitantly with a transient decrease in series conductance (Gs, Fig. $1 \mathrm{~A})$. The electrophysiological characteristics shown in Fig. 1 have been defined as bulk-like endocytosis (Wu and Wu, 2007).

Because similar responses were also obtained in insulin-secreting INS-1 cells (Fig. 1B), we performed molecular manipulations in INS-1 cells. An average step-like capacitance decline of $19 \pm 0.7 \mathrm{fF}$ was recorded in cells with levels of $\left[\mathrm{Ca}^{2+}\right]_{i}$ elevated to approximately $20 \mu \mathrm{mol} / \mathrm{L}$, which corresponded to the scission of a vacuole of approximately $780 \mathrm{~nm}$ in diameter (assuming $1 \mathrm{fF} / \mathrm{\mu m}^{2}$ as the specific membrane capacitance). When we knocked down clathrin in INS-1 cells (He et al., 2008), the capacitance drops persisted with similar amplitude (19 $\pm 1 \mathrm{fF}$ ) and frequency (clathrin shRNA, $0.54 \pm$ 0.11 event/s, $n=15$; control, $0.51 \pm 0.04$ event/s, $n=40$ ), which confirmed their association with clathrin-independent endocytosis (Fig. 1D). This clathrin-independent endocytosis is obviously different from the "cavicapture" model, in which similar increases and decreases in capacitance are observed during large fusion pore flickering (MacDonald et al., 2006).

We also tested whether bulk-like endocytosis occurred under physiological-relevant stimulation. To record bulk-like endocytosis, we used trains of $200 \mathrm{~ms}$ depolarization $(1 \mathrm{~Hz})$ from $-70 \mathrm{mV}$ to $0 \mathrm{mV}$ to repetitively depolarize primary pancreatic beta cells (using an interval of $10 \mathrm{~s}$ after each sweep), thereby simulating the membrane potential oscillation of the beta cells during blood glucose elevation. Indeed, bulk-like endocytosis was observed in $39.3 \%$ of the beta cells (12/28 cells) under the standard whole-cell configuration (an example is shown in Fig. 2). The time required for bulk-like endocytosis to occur was variable, and bulk-like retrieval events can be observed during both the depolarization sweep (synchronized) and the interval between different sweeps (asynchronized). We also directly tested whether physiological stimulation induced bulk-like endocytosis in vivo using electron microscopy. Occasionally, large invaginations connected to the plasma membrane could be observed after intact islets were stimulated with $\mathrm{KCl}$ (Fig. 2D). More frequently, fused chain of insulin granules were observed in the primary beta cells (Fig. 2A, arrow), similar to previous reports (Kwan and Gaisano, 2005; Hoppa et al., 2012). They collapse into the plasma membrane and release insulin in a multiple-granular manner (Fig. $2 \mathrm{C}$ ) and can be retrieved back as a whole unit (Fig. 2B, arrowhead), which may suggest a type of bulk-like membrane retrieval.

\section{Depolarization-induced bulk-like endocytosis is $\mathrm{Ca}^{2+}$ and dynamin dependent}

Wu et al. demonstrated that $\mathrm{Ca}^{2+}$ initiates bulk-like endocytosis during depolarization at calyx nerve terminals (Wu et al., 2009). Similarly, we attempted to determine whether the bulk- like endocytosis in primary beta cells depends on the amount of calcium that enters the cells. A depolarization train evokes an approximately $20 \%$ greater capacitance in a $10 \mathrm{mmol} / \mathrm{L} \mathrm{Ca}^{2+}$ bath solution compared with a $2.6 \mathrm{mmol} / \mathrm{L} \mathrm{Ca}^{2+}$ bath solution (Fig. 3A and $3 \mathrm{~B}$ ). In contrast, depolarization in a $10 \mathrm{mmol} / \mathrm{L} \mathrm{Ca}^{2+}$ bath solution evoked an approximately 2.5 -fold increase in the frequency but not the average amplitude of bulk-like endocytosis (the mean frequency was $0.010 \pm 0.003 \mathrm{~Hz}$ in $2.6 \mathrm{mmol} / \mathrm{L} \mathrm{Ca}^{2+}$ compared with $0.025 \pm 0.005 \mathrm{~Hz}$ in $10 \mathrm{mmol} / \mathrm{L} \mathrm{Ca}^{2+}, P<0.05$ ) (Fig. 3C and 3D). The increased number of bulk-like events was primarily due to an increase in the bulk retrieval during the intervals between the depolarization trains $(P=0.08$, Fig. 3E), which suggested that bulk-like endocytosis is a delayed mechanism that is triggered by prolonged $\mathrm{Ca}^{2+}$ elevation.

Dynamin is a large GTPase that is principally involved in the scission of newly formed vesicles from the membrane (Cao et al., 1998). Dephosphorylation of dynamin I has been demonstrated to participate in activity dependent bulk endocytois in neurons. To verify the role of dynamin in bulk-like endocytosis in pancreatic beta cells, we preincubated beta cells in RPMI 1640 with $80 \mu \mathrm{mol} / \mathrm{L}$ dynasore for $30 \mathrm{~min}$, which potently inhibits dynamin function (Macia et al., 2006; Newton et al., 2006). Thereafter, cells were transferred to a recording chamber containing $10 \mathrm{mmol} / \mathrm{L} \mathrm{Ca}^{2+}$ and $80 \mu \mathrm{mol} / \mathrm{L}$ dynasore (to prevent a washout effect). In contrast to previous reports (Tsai et al., 2009; Wu et al., 2009), short-term pretreatment with dynasore did not inhibit exocytosis. Instead, depolarization evoked an approximately 2 -fold increase in capacitance in the $10 \mathrm{mmol} / \mathrm{L} \mathrm{Ca}^{2+}$ solution (Fig. $3 \mathrm{~A}$ and $3 \mathrm{~B}$ ) and significantly reduced the frequency of the delayed bulk-like event (Fig. 3D and 3E). Given that knocking-down of clathrin did not affect bulk-like endocytosis (Fig. 1), dynamin may play a clathrin -independent facilitatory role in stimulation -activated bulk-like endocytosis in primary beta cells. 
A

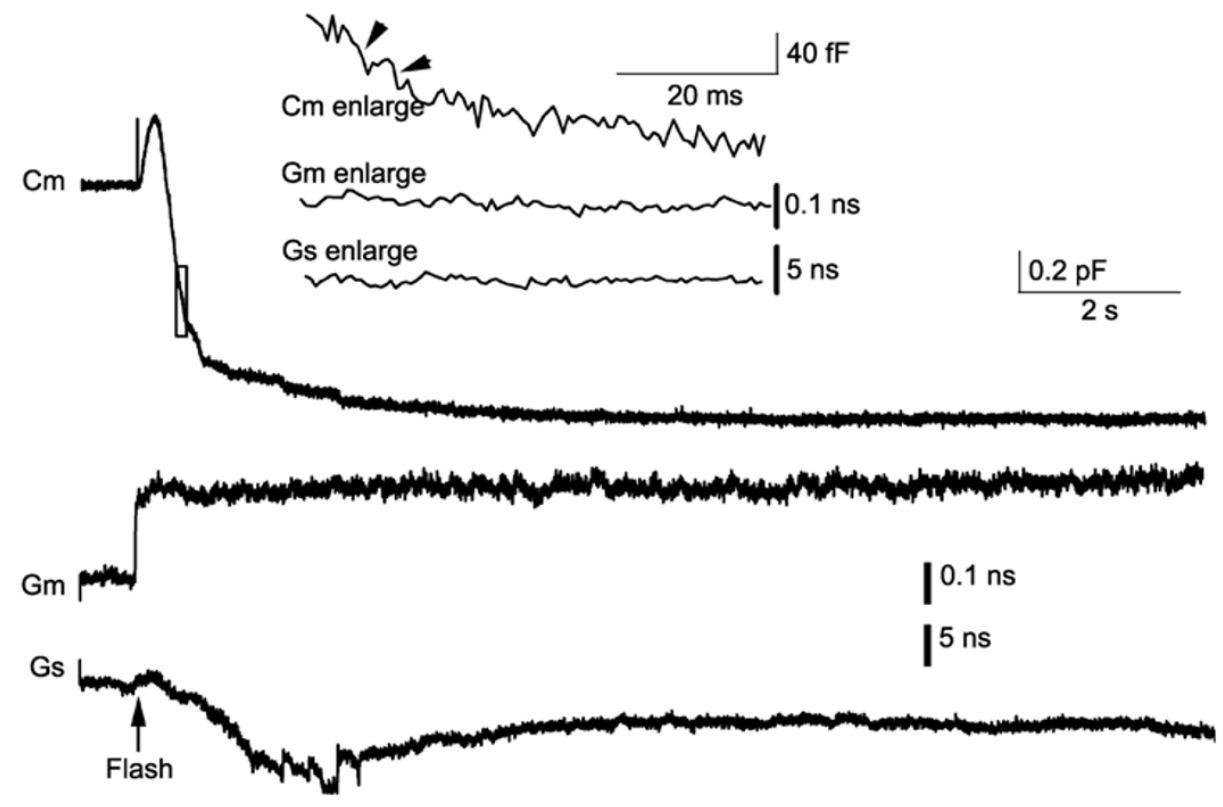

B

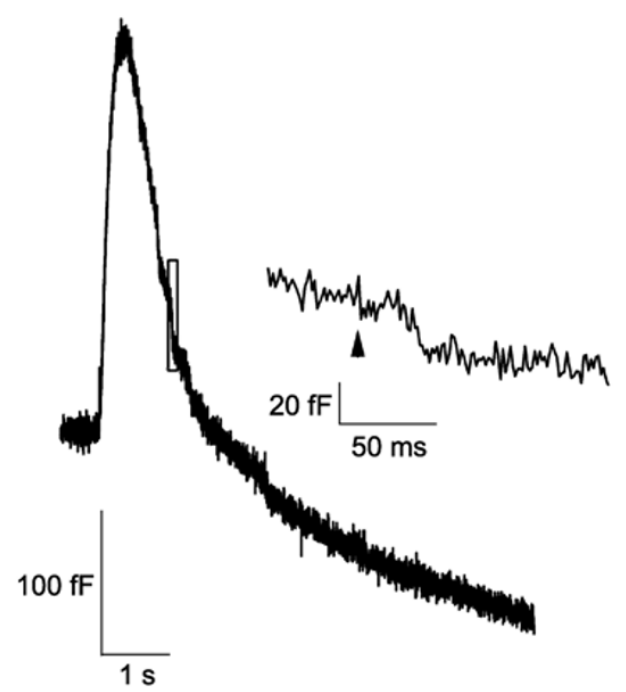

C

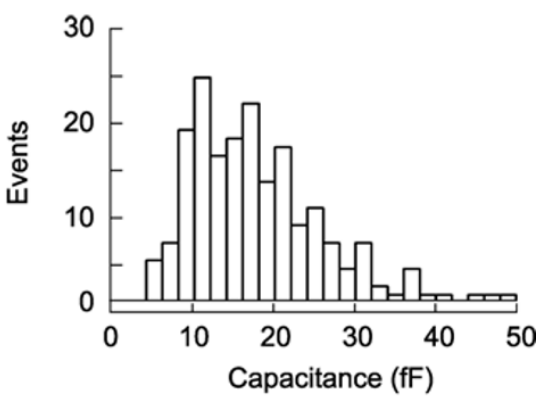

D

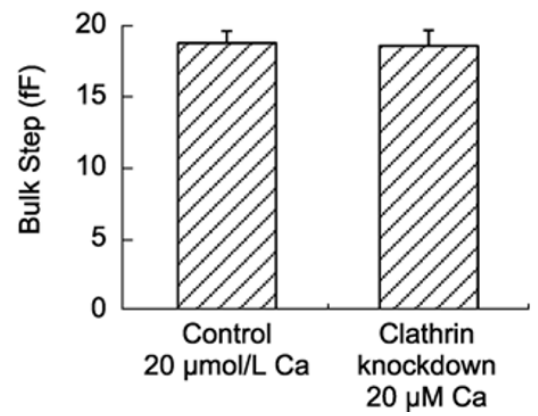

Figure 1. Flash photolysis can elicit clathrin-independent bulk-like endocytosis. (A and B) An example of UV photolysis-induced fast decay in the capacitance of primary beta cells and INS-1 cells. The trace enclosed in the red box is enlarged in the inset, which shows a single step-like decrease in capacitance. (C) The size histogram of the step-like capacitance declines in INS-1 cells after a homogenous increase in $\left[\mathrm{Ca}^{2+}\right]_{\mathrm{i}}$ to aproximately $20 \mu \mathrm{mol} / \mathrm{L}$. (D) A summary of the average step-like capacitance decreases in control INS-1 cells $\left(\left[\mathrm{Ca}^{2+}\right]_{\mathrm{i}}\right.$ approximately $\left.20 \mu \mathrm{mol} / \mathrm{L}, n=203\right)$ and in INS-1 cells where clathrin expression was knocked down ([Ca $\left.{ }^{2+}\right]_{\mathrm{i}}$ approximately $\left.20 \mu \mathrm{mol} / \mathrm{L}, n=81\right)$.

Impairment of the bulk-like endocytic mechanism in beta cells from diabetic KKAy mice

Insulin secretion from pancreatic beta cells plays a crucial role in the regulation of blood glucose homeostasis. Therefore, it is well accepted that type II diabetes involves a perturbation of the exocytotic machinery of pancreatic beta cells (Eliasson et al., 2008). However, whether changes in the 
A

Depolarization Model
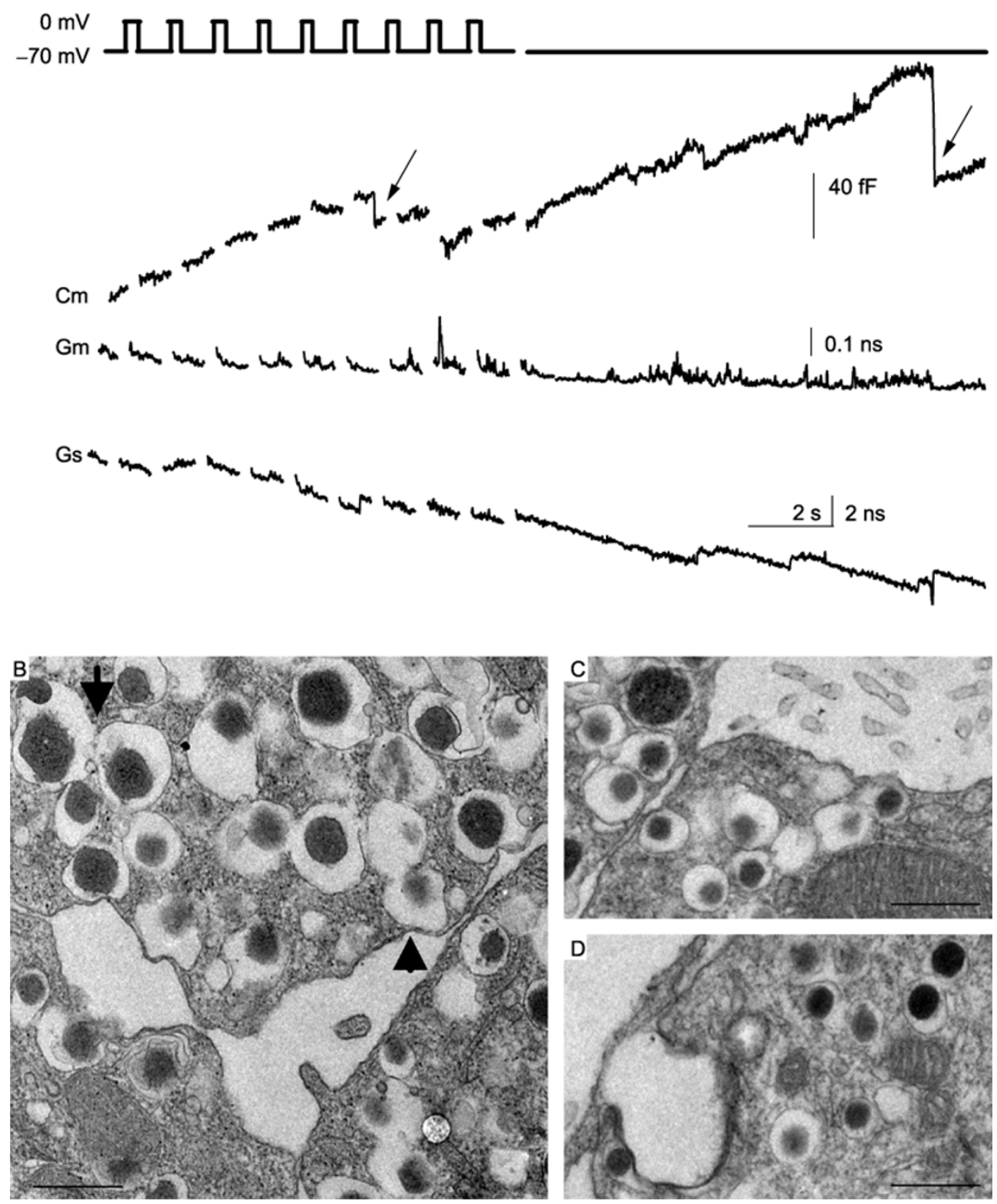

Figure 2. Depolarization elicit bulk-like endocytosis in pancreatic $\boldsymbol{\beta}$ cells. (A) Trains of ten 200-ms pulses (frequency $1 \mathrm{~Hz}$ ) induced a capacitance jump ( $\mathrm{Cm})$, except for abrupt bulk endocytosis (arrows). The measured values of $\mathrm{Gm}$ and $\mathrm{Gs}$ are shown below the figure. (B) After $5 \mathrm{~min}$ of $20 \mathrm{mmol} / \mathrm{L}$ glucose stimulation, two insulin glanules are contacted and fused with each other (indicated by arrow) and three fused glanules are retrieval together after the release of the contents (indicated by arrow head). (C) Secretory granules fuse together (also partially emptied) after $70 \mathrm{mmol} / \mathrm{L} \mathrm{KCl} \mathrm{stimulation} \mathrm{for} 5 \mathrm{~min}$. (D) Large invagination coonected to the plasma membrane after $70 \mathrm{mmol} / \mathrm{L} \mathrm{KCl}$ stimulation. Scale bar: $500 \mathrm{~nm}$ in all EM figures.

membrane recycling process participate in such pathological processes has not been investigated. We used yellow-coated KKAy mice that exhibit spontaneous hyperglycemia and glucose intolerance at 8 weeks of age (Srinivasan and Ramarao, 2007). Consistent with a previous report (Srinivasan and Ramarao, 2007), KKAy mice had greater body weight than age-mated C57BI/6 controls (Fig. 4A) and exhibited impaired glucose tolerance and pronounced insulin resistance at 10 weeks (Fig, 4B and 4C). Compared with the control group, depolarization evoked a greater than two-fold increase in capacitance in KKAy beta cells in both $2.6 \mathrm{mmol} / \mathrm{L}$ and $10 \mathrm{mmol} / \mathrm{L} \mathrm{Ca}^{2+}$ bath solutions (Fig. $4 \mathrm{D}$ and $4 \mathrm{E}$ ), which is 


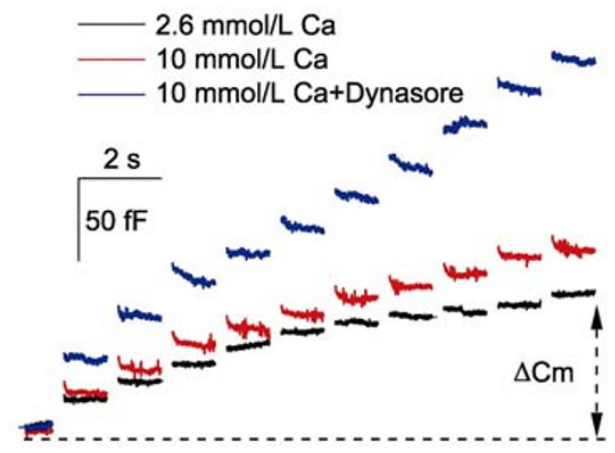

B

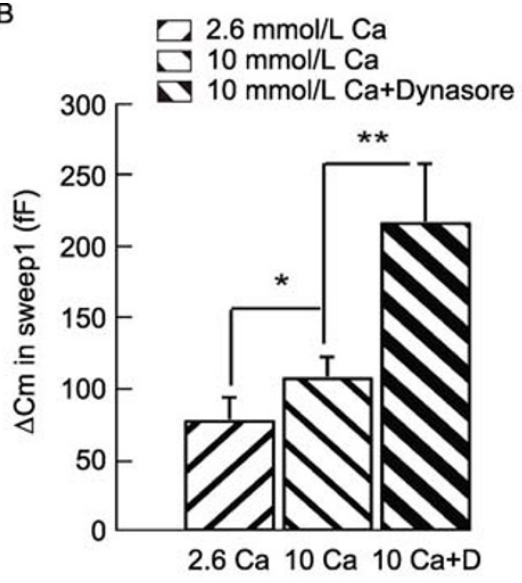

C

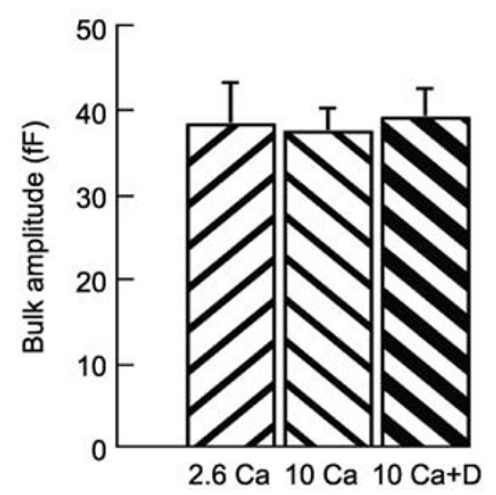

D

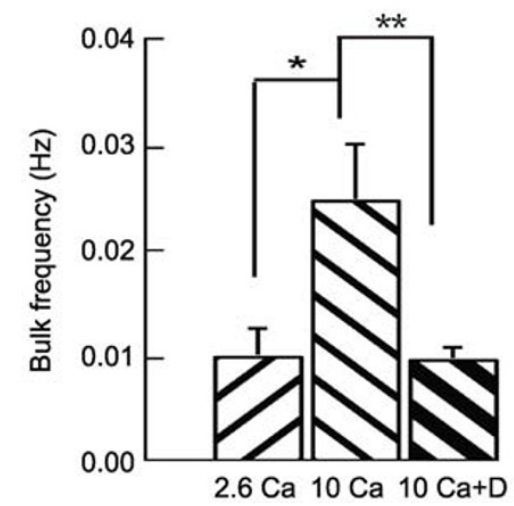

E

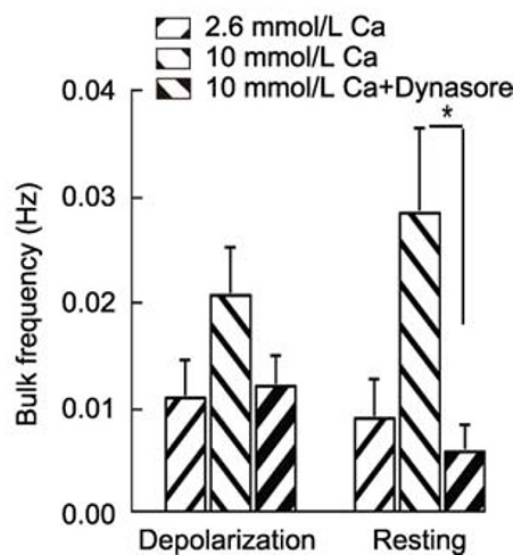

Figure 3. Depolarization-induced bulk-like endocytosis is $\mathbf{C a 2 +}$ and dynamin dependent. (A) The average $\mathrm{Cm}$ traces induced by ten $200-\mathrm{ms}$ pulses (frequency $1 \mathrm{~Hz}$ ) in $2.6 \mathrm{mmol} / \mathrm{L} \mathrm{Ca}^{2+}$ (black), $10 \mathrm{mmol} / \mathrm{L} \mathrm{Ca}^{2+}$ (red) or $10 \mathrm{mmol} / \mathrm{L} \mathrm{Ca}{ }^{2+}$ plus $80 \mu \mathrm{mol} / \mathrm{L}$ dynasore (blue) $\left(2.6 \mathrm{mmol} / \mathrm{L} \mathrm{Ca}^{2+}, n=28 ; 10 \mathrm{mmol} / \mathrm{L} \mathrm{Ca}^{2+}, n=31 ; 10 \mathrm{mmol} / \mathrm{L} \mathrm{Ca}^{2+}\right.$ plus $80 \mu \mathrm{mol} / \mathrm{L}$ dynasore, $\left.n=17\right)$. (B) The average capacitance jump $(\triangle \mathrm{Cm})$ in the first sweep. (C and $\mathrm{D})$ The average bulk amplitude and frequency under the three conditions ( $\left.{ }^{\star} P<0.05,{ }^{\star *} P<0.01\right)$. (E) The average bulk frequency during the depolarization time and the resting time $\left({ }^{\star} P<0.05\right)$.

consistent with the beta cell hyperinsulinemia reported at an earlier stage in diabetic animals or patients (Homo-Delarche, 1997; Liang et al., 2011). Although the mean amplitude of bulk-like endocytosis was not changed, markedly fewer bulk-like retrieval events were observed in the diabetic beta cells stimulated in either $2.6 \mathrm{mmol} / \mathrm{L}$ or $10 \mathrm{mmol} / \mathrm{L} \mathrm{Ca}^{2+}$ bath solutions (Fig. 4F and 4G). Taken together, these data suggest that bulk-like endocytosis is severely impaired in pancreatic beta cells isolated from diabetic KKAy mice.

\section{DISSCUSION}

Eliasson et al. was the first author to report the induction of endocytosis by transient elevation of cytosolic calcium in mouse pancreatic beta cells, including large amplitude capacitance fluctuations that resemble bulk endocytosis (Eliasson et al., 1996). Our data corroborate their findings by demonstrating bulk-like endocytosis evoked by both flash photolysis and whole-cell depolarization in primary beta cells. Moreover, we show that bulk-like endocytosis is not altered when endogenous clathrin is knocked down with shRNA, which has been demonstrated to inhibit both transferrin internalization and clathrin-mediated slow endocytosis in a previous study by our group (He et al., 2008). Although clathrin-coated pits have been shown to bud from large infoldings on the plasma membrane (Lenzi et al., 2002), we believe that bulk-like endocytosis in beta cells is a clathrinindependent process. Interestingly, studies have proposed that calcium activates bulk-like endocytosis in various types of neurons (Clayton et al., 2009; Wu et al., 2009). Qualitatively, our data fit with the hypothesis that bulk-like endocytosis is a $\mathrm{Ca}^{2+}$-dependent process because enhanced $\mathrm{Ca}^{2+}$ influx doubled the frequency of bulk endocytosis, whereas only $30 \%$ increase in exocytosis was observed. However, high levels of $\mathrm{Ca}^{2+}$ in the bath solution did not enhance the mean amplitude of bulk-like endocytic events and failed to affect the 
A

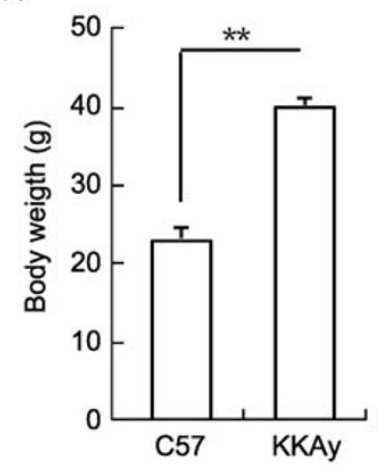

B

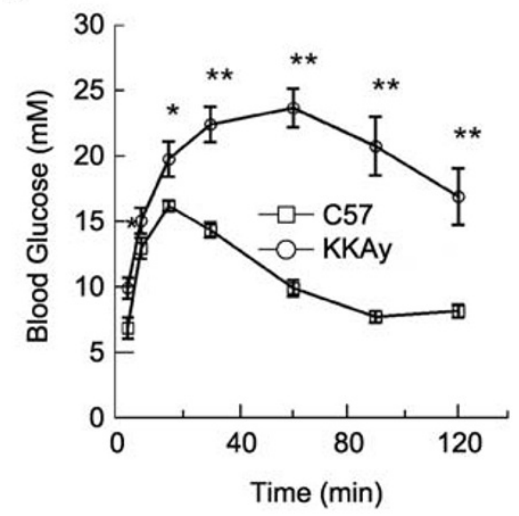

C

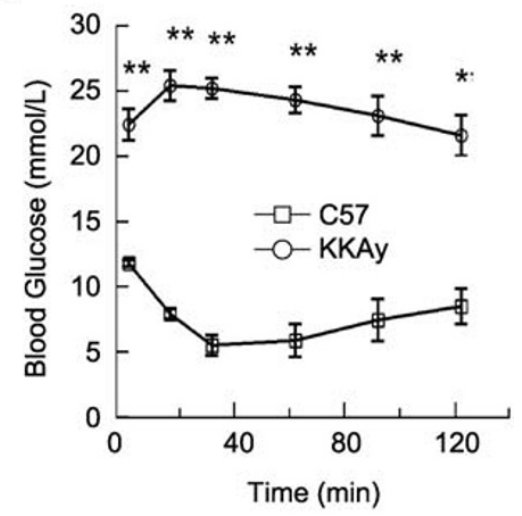

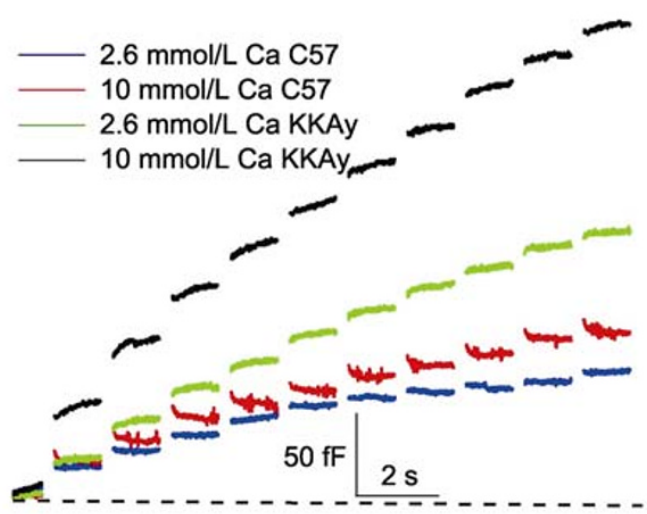

F

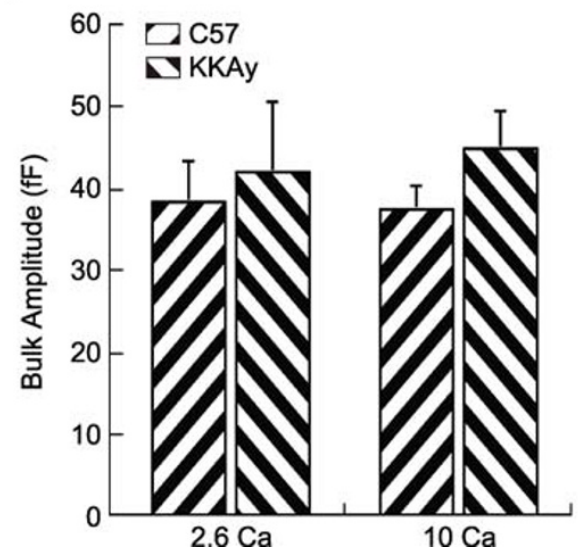

E

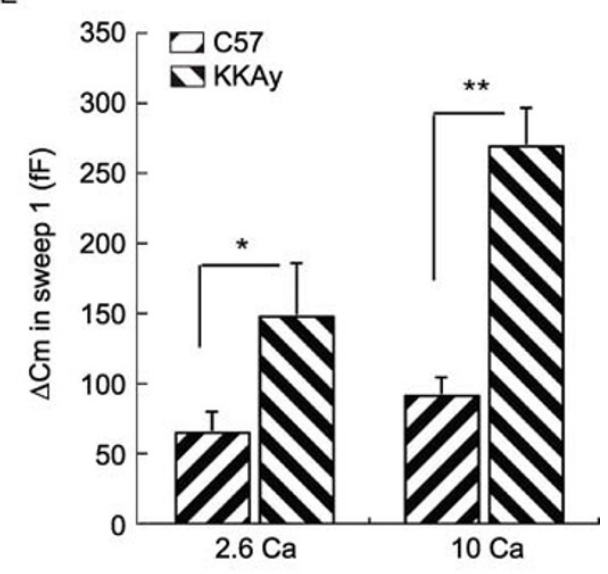

G

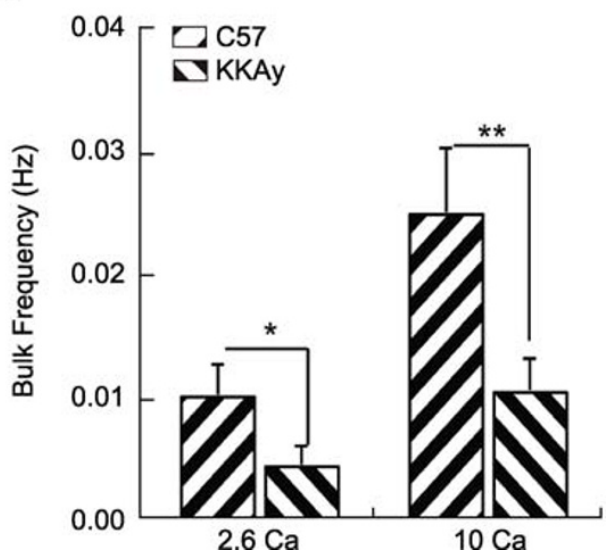

Figure 4. Impairment of the bulk-like endocytic mechanism in beta cells from diabetic KKAy mice. Comparison of (A) body weight, (B) blood glucose during GTT (i.p. administration of $2 \mathrm{~g} / \mathrm{kg}$ body weight glucose), and (C) blood glucose during ITT (i.p. administration of $0.5 \mathrm{U} / \mathrm{kg}$ body weight insulin) between C57BI/6 and KKAy mice. (D) The average Cm traces induced by ten 200-ms pulses (frequency $1 \mathrm{~Hz}$ ) in $\mathrm{C} 57$ and KKAy beta cells (blue, $2.6 \mathrm{mmol} / \mathrm{L} \mathrm{Ca}^{2+}, \mathrm{C} 57, n=28$; green, $2.6 \mathrm{mmol} / \mathrm{L} \mathrm{Ca}{ }^{2+}, \mathrm{KKAy}$, $n=25$; red, $10 \mathrm{mmol} / \mathrm{L} \mathrm{Ca}^{2+}, \mathrm{C} 57, n=31$; black, $\left.10 \mathrm{mmol} / \mathrm{L} \mathrm{Ca}^{2+}, \mathrm{KKAy}, n=15\right)$. Beta cells from C57 and KKAy mice are of similar size in resting condition ( $C 57$ beta cells, $\left.\mathrm{C}_{\text {slow }}=5.0 \pm 0.1 \mathrm{pF} ; \mathrm{KKAy} \mathrm{C}_{\text {slow }}=4.9 \pm 0.3 \mathrm{pF}\right)$. (E) The average capacitance jump $(\Delta \mathrm{Cm})$ in the first sweep. ( $F$ and $\mathrm{G}$ ) The average bulk amplitude and frequency under $2.6 \mathrm{mmol} / \mathrm{L} \mathrm{Ca}$ and $10 \mathrm{mmol} / \mathrm{L}$ Ca conditions $\left({ }^{*} P<0.05\right.$, $\left.{ }^{* *} P<0.01\right)$. 
frequency of bulk retrieval during the depolarization (Fig. $3 \mathrm{~A}$ and $3 C$ ). This suggests that the stimulatory effect of $\mathrm{Ca}^{2+}$ on bulk-like endocytosis is facilitatory rather than obligatory.

Although inhibition of dynamin function with dynasore in primary beta cells failed to inhibit exocytosis, it abolished the stimulatory effects of the high bath concentration of $\mathrm{Ca}^{2+}$ on bulk-like endocytosis, which is consistent with the function of $\mathrm{Ca}^{2+}$ and dynamin in the same pathway in bulk-like endocytosis. Bulk-like endocytosis is activated by strong stimulation in neurons (Clayton et al., 2008). In parallel, elevated $\mathrm{Ca}^{2+}$ activates the calcium/calmodulin -dependent protein phosphatase calcineurin, which leads to the dephosphorylation of dynamin I and its interaction with the F-BAR protein, syndapin I (Anggono et al., 2006; Clayton et al., 2009). Therefore, our data appear to agree with the specific role of dynamin I rephosphorylation at SER-774 in bulk-like endocytosis in neurons (Clayton et al., 2010). Interestingly, bulk-like endocytosis persisted during depolarization in cells pretreated with dynasore, which argues against the mandatory role of dynamin in bulk-like endocytosis. Similarly, many more endosome-like structures have been observed in dynamin I KO synapses after acute strong stimulation compared with control synapses (Hayashi et al., 2008), which indicates the existence of a bulk retrieval mechanism that is independent of dynamin I. Therefore, we postulate that neither $\mathrm{Ca}^{2+}$ nor dynamin is required for the initiation of clathrin-independent bulk-like endocytosis; however, they facilitate bulk -like endocytosis in an activity-dependent manner. In addition, extremely high increases in the intracellular calcium concentration evoked by flash photolysis may temporally coordinate different bulk-like endocytic events that contribute to the rapid clathrin-independent phase of endocytosis that has been observed in primary beta cells and corticotrophs (Eliasson et al., 1996; Lee and Tse, 2001; He et al., 2008).

Although bulk-like endocytosis has been found in a number of neurons and endocrine cells, its mechanism and physiological significance remain elusive. Bulk-like endocytosis has been proposed to be a retrieval mechanism evoked by conditions under which classical endocytosis cannot match pace with exocytosis (e.g., dynamin I knockout or clathrin-inactivation during high-frequency stimulation) (Hayashi et al., 2008; Heerssen et al., 2008). Moreover, the intermediate organelle generated by bulk-like endocytosis is proposed to be incapable of efficiently generating fusion-competent synaptic vesicles (Hayashi et al., 2008; Heerssen et al., 2008). However, compound exocytosis of prefused insulin granules was reported in rat pancreatic beta cells in 2005 (Kwan and Gaisano, 2005). Recently, compound exocytosis has been further demonstrated to play a important role under conditions associated with the global elevation of cytosolic $\mathrm{Ca}^{2+}$ (Hoppa et al., 2012), which is the condition that augments the bulk-like endocytosis found in the present study. Our electron microscope data also show examples of compound fusion of several granules to the plasma membrane (Fig. 2C) and retrieval of three inter-connected nearly empty vacuoles (Fig. 2B, arrowhead). Therefore, bulk-like endocytosis may be a result of compound or sequential exocytosis evoked by physiological stimulation in pancreatic beta cells. Most importantly, we demonstrate the selected reduction of bulk-like endocytosis in beta cells isolated from mice at earlier stage of diabetes. This contrasts with the enhanced insulin secretion from the beta cells compared with the control cells. Because bulk-like endocytosis may play an important role in the recycling of insulin granules, the combination of defective recycling and enhanced secretion will lead to the run-down and down-regulation of beta cell secretory ability as diabetes progresses, which has been observed in human diabetic patients (Ostenson et al., 2006). Therefore, elucidating the molecular mechanism of bulk-like endocytosis and discovering reagents that upregulate the endocytic pathway may prolong the preservation of primary beta cell function and postpone the onset of type II diabetes.

\section{MATERIALS AND METHODS}

\section{Islets and single beta cell preparation}

C57BL/6 male mice were purchased from the Vital River Experimental Animal Company, Beijing, China, and age-mated KKAy mice were purchased from the Institute of Laboratory Animal Science at the Chinese Academy of Medical Sciences, Beijing, China. All of the mice were maintained under specific pathogen-free conditions. The handling of the mice and the experimental procedures were conducted in accordance with the Committee of the Use of Live Animals in Teaching and Research at the Institute of Biophysics at the Chinese Academy of Sciences. The mice were sacrificed by cervical dislocation, and primary islets and beta cells were isolated as previously described. The isolated cells were plated on coverslips precoated with poly-l-lysine and maintained in a $37^{\circ} \mathrm{C}, 5 \% \mathrm{CO}_{2}$ incubator for 24-48 $\mathrm{h}$ in modified RPMI 1640 medium. We selected cells with diameters $>11 \mu \mathrm{mol} / \mathrm{L}$ with the expectation that more than $80 \%-90 \%$ of the cells would be beta cells (Rorsman and Trube, 1986) more than.

\section{Patch capacitance measurements}

Electrophysiological experiments were conducted with standard whole-cell recordings using an EPC-10 patch-clamp amplifier (HEKA). The bath solution contained (mmol/L) $138 \mathrm{NaCl}, 5.6 \mathrm{KCl}, 1.2 \mathrm{MgCl}_{2}$, $2.6 \mathrm{CaCl}_{2}, 5$ glucose, and $10 \mathrm{HEPES}$ ( $\mathrm{pH} 7.4$, adjusted with $\mathrm{NaOH}$ ). For the flash experiments, the intracellular solution contained (mmol/L) 105 Cs- Glutamate, 2 MgATP, 0.3 GTP, 33 HEPES, 0.4 Mag-Fura-2, 0.4 Fura-4F, $4 \mathrm{CaCl}_{2}$, and 5 NP-EGTA (pH 7.2, adjusted with $\mathrm{NaOH}$ or $\mathrm{HCl}$ ). For the depolarization experiments, the pipette solution contained (mmol/L) 125 Cs-Glutamate, 2 Mg-ATP, 0.3 $\mathrm{Na}_{2}$-GTP, $1 \mathrm{MgCl}_{2}$, and 0.1 EGTA ( $\mathrm{pH} 7.2$, adjusted with $\mathrm{CsOH}$ ). In addition, $10 \mathrm{mmol} / \mathrm{L}$ TEA-Cl and $2 \mathrm{mmol} / \mathrm{L}$ forskolin were added to the bath solution. The extracellular calcium concentration was 2.6 $\mathrm{mmol} / \mathrm{L}$ unless otherwise indicated. Capacitance measurements were performed using the 'sine + DC' mode of the software lock-in extension of Pulse software. An $800-\mathrm{Hz}, 20-\mathrm{mV}$ peak-to-peak sinu- 
soidal voltage stimulus was applied at a DC holding potential of -70 $\mathrm{mV}$. Ten trains of depolarization (from $-70 \mathrm{mV}$ to $0 \mathrm{mV}$ for $200 \mathrm{~ms}$ ) were applied to single beta cells to evoke an increase in capacitance, which was indicative of insulin secretion. Flash photolysis and increases in the membrane capacitance were performed as previously described (Duman et al., 2006).

\section{Transmission electron microscopy}

The mouse islets were grown in culture medium for one day before being harvested. On the day of experiments, islets were stimulated with either $70 \mathrm{mmol} / \mathrm{L} \mathrm{KCl}$ or $20 \mathrm{mmol} / \mathrm{L}$ glucose for 5 minute before fixed in $2.5 \%$ glutaraldehyde in PBS $(\mathrm{pH} 7.4)$ at room temperature for $30 \mathrm{~min}$. The islets were then postfixed with $1 \%$ osmium tetroxide in $0.1 \mathrm{M}$ sodium cacodylate for one hour. Following dehydration in a graded acetone series, the samples were embedded in Embed 812 and sliced into 70-nm sections using a Leica ultramicrotome EM UC6 (Leica, Germany). After being contrasted with uranyl acetate and lead citrate, the sections were observed under a Spirit transmission electron microscope (FEI, the Netherlands).

\section{Intraperitoneal glucose tolerance and insulin resistance tests}

For the intraperitoneal glucose tolerance test (IGTT), the mice were starved overnight and then given an i.p. glucose injection $(2 \mathrm{~g} / \mathrm{kg}$ body weight). Venous blood was drawn from the tail vein, and the blood glucose level was measured using a glucometer (ACCU-CHEK Active, Roche). For the insulin tolerance test (ITT), the mice were starved for 4-5 hours prior to an i.p. injection of $0.5 \mathrm{U} / \mathrm{kg}$ body weight of human regular insulin (Sigma-Aldrich, St. Louis, MO, USA). Blood glucose levels were measured using a glucometer.

\section{Data analysis}

All of the data were analyzed using Igor Pro software (Wavemetrics, Lake Oswego, OR). The results are presented as the mean value \pm SEM. Statistical significance was evaluated using either Student's $t$ test for single Gaussian distributed datasets or the Mann-Whitney rank sum test for non-single Gaussian distributed datasets. The symbols * and ** denote statistical significance with $P$ values of less than 0.05 and 0.01 , respectively.

\section{ACKNOWLEDGEMENTS}

This work was supported by a grant from the National Natural Science Foundation of China (Grant No. 30871225), a grant from Beijing Municipal Science and Technology Commission (Grant No. 7121008), a grant from the Ministry of Science and Technology (Grant No. SQ2011SF11B01041) and the fund from The Key Construction Program of the National "985" Project from the Department of Education of China to Peking University.

\section{REFERENCES}

Anggono, V., Smillie, K.J., Graham, M.E., Valova, V.A., Cousin, M.A., and Robinson, P.J. (2006). Syndapin I is the phosphorylation-regulated dynamin I partner in synaptic vesicle endocytosis. Nat Neurosci 9, 752-760.

Cao, H., Garcia, F., and McNiven, M.A. (1998). Differential distribution of dynamin isoforms in mammalian cells. Mol Biol Cell 9, 2595-2609.

Clayton, E.L., Anggono, V., Smillie, K.J., Chau, N., Robinson, P.J., and Cousin, M.A. (2009). The phospho-dependent dynaminsyndapin interaction triggers activity-dependent bulk endocytosis of synaptic vesicles. J Neurosci 29, 7706-7717.

Clayton, E.L., and Cousin, M.A. (2009). The molecular physiology of activity-dependent bulk endocytosis of synaptic vesicles. J Neurochem 111, 901-914.

Clayton, E.L., Evans, G.J., and Cousin, M.A. (2008). Bulk synaptic vesicle endocytosis is rapidly triggered during strong stimulation. $J$ Neurosci 28, 6627-6632.

Clayton, E.L., Sue, N., Smillie, K.J., O'Leary, T., Bache, N., Cheung, G., Cole, A.R., Wyllie, D.J., Sutherland, C., Robinson, P.J., et al. (2010). Dynamin I phosphorylation by GSK3 controls activitydependent bulk endocytosis of synaptic vesicles. Nat Neurosci 13, 845-851.

Duman, J.G., Chen, L., Palmer, A.E., and Hille, B. (2006). Contributions of intracellular compartments to calcium dynamics: implicating an acidic store. Traffic 7, 859-872.

Eliasson, L., Abdulkader, F., Braun, M., Galvanovskis, J., Hoppa, M.B., and Rorsman, P. (2008). Novel aspects of the molecular mechanisms controlling insulin secretion. J Physiol 586, 3313-3324.

Eliasson, L., Proks, P., Ammala, C., Ashcroft, F.M., Bokvist, K., Renstrom, E., Rorsman, P., and Smith, P.A. (1996). Endocytosis of secretory granules in mouse pancreatic beta-cells evoked by transient elevation of cytosolic calcium. J Physiol 493 ( Pt 3), 755-767.

Hayashi, M., Raimondi, A., O'Toole, E., Paradise, S., Collesi, C., Cremona, O., Ferguson, S.M., and De Camilli, P. (2008). Celland stimulus-dependent heterogeneity of synaptic vesicle endocytic recycling mechanisms revealed by studies of dynamin 1-null neurons. Proc Natl Acad Sci U S A 105, 2175-2180.

He, Z., Fan, J., Kang, L., Lu, J., Xue, Y., Xu, P., Xu, T., and Chen, L. (2008). $\mathrm{Ca}^{2+}$ triggers a novel clathrin-independent but actindependent fast endocytosis in pancreatic beta cells. Traffic 9, 910-923.

Heerssen, H., Fetter, R.D., and Davis, G.W. (2008). Clathrin dependence of synaptic-vesicle formation at the Drosophila neuromuscular junction. Curr Biol 18, 401-409.

Homo-Delarche, F. (1997). Beta-cell behaviour during the prediabetic stage. Part II. Non-insulin-dependent and insulin-dependent diabetes mellitus. Diabetes Metab 23, 473-505.

Hoppa, M.B., Jones, E., Karanauskaite, J., Ramracheya, R., Braun, M., Collins, S.C., Zhang, Q., Clark, A., Eliasson, L., Genoud, C., et al. (2012). Multivesicular exocytosis in rat pancreatic beta cells. Diabetologia 55, 1001-1012.

Kwan, E.P., and Gaisano, H.Y. (2005). Glucagon-like peptide 1 regulates sequential and compound exocytosis in pancreatic islet beta-cells. Diabetes 54, 2734-2743.

Lee, A.K., and Tse, A. (2001). Endocytosis in identified rat corticotrophs. J Physiol 533, 389-405. 
Lenzi, D., Crum, J., Ellisman, M.H., and Roberts, W.M. (2002). Depolarization redistributes synaptic membrane and creates a gradient of vesicles on the synaptic body at a ribbon synapse. Neuron 36, 649-659.

Liang, K., Du, W., Zhu, W., Liu, S., Cui, Y., Sun, H., Luo, B., Xue, Y., Yang, L., Chen, L., et al. (2011). Contribution of different mechanisms to pancreatic beta-cell hyper-secretion in non-obese diabetic (NOD) mice during pre-diabetes. J Biol Chem 286, 39537-39545.

MacDonald, P.E., Braun, M., Galvanovskis, J., and Rorsman, P. (2006). Release of small transmitters through kiss-and-run fusion pores in rat pancreatic beta cells. Cell Metab 4, 283-290.

Macia, E., Ehrlich, M., Massol, R., Boucrot, E., Brunner, C., and Kirchhausen, T. (2006). Dynasore, a cell-permeable inhibitor of dynamin. Dev Cell 10, 839-850.

Newton, A.J., Kirchhausen, T., and Murthy, V.N. (2006). Inhibition of dynamin completely blocks compensatory synaptic vesicle endocytosis. Proc Natl Acad Sci U S A 103, 17955-17960.

Orci, L., Malaisse-Lagae, F., Ravazzola, M., Amherdt, M., and Renold, A.E. (1973). Exocytosis-endocytosis coupling in the pancreatic beta cell. Science 181, 561-562.

Ostenson, C.G., Gaisano, H., Sheu, L., Tibell, A., and Bartfai, T. (2006). Impaired gene and protein expression of exocytotic soluble $\mathrm{N}$-ethylmaleimide attachment protein receptor complex proteins in pancreatic islets of type 2 diabetic patients. Diabetes $55,435-440$.

Paillart, C., Li, J., Matthews, G., and Sterling, P. (2003). Endocytosis and vesicle recycling at a ribbon synapse. J Neurosci 23,
4092-4099.

Richards, D.A., Guatimosim, C., and Betz, W.J. (2000). Two endocytic recycling routes selectively fill two vesicle pools in frog motor nerve terminals. Neuron 27, 551-559.

Rorsman, P., and Trube, G. (1986). Calcium and delayed potassium currents in mouse pancreatic beta-cells under voltage-clamp conditions. J Physiol 374, 531-550.

Royle, S.J., and Lagnado, L. (2003). Endocytosis at the synaptic terminal. J Physiol 553, 345-355.

Srinivasan, K., and Ramarao, P. (2007). Animal models in type 2 diabetes research: an overview. Indian J Med Res 125, 451-472.

Takei, K., Mundigl, O., Daniell, L., and De Camilli, P. (1996). The synaptic vesicle cycle: a single vesicle budding step involving clathrin and dynamin. J Cell Biol 133, 1237-1250.

Teng, H., Cole, J.C., Roberts, R.L., and Wilkinson, R.S. (1999). Endocytic active zones: hot spots for endocytosis in vertebrate neuromuscular terminals. J Neurosci 19, 4855-4866.

Tsai, C.C., Lin, C.L., Wang, T.L., Chou, A.C., Chou, M.Y., Lee, C.H., Peng, I.W., Liao, J.H., Chen, Y.T., and Pan, C.Y. (2009). Dynasore inhibits rapid endocytosis in bovine chromaffin cells. Am J Physiol Cell Physiol 297, C397-406.

Wu, W., and Wu, L.G. (2007). Rapid bulk endocytosis and its kinetics of fission pore closure at a central synapse. Proc Natl Acad Sci U S A 104, 10234-10239.

Wu, X.S., McNeil, B.D., Xu, J., Fan, J., Xue, L., Melicoff, E., Adachi, R., Bai, L., and Wu, L.G. (2009). Ca(2+) and calmodulin initiate all forms of endocytosis during depolarization at a nerve terminal. Nat Neurosci 12, 1003-1010. 